\title{
Investigation of the Fire, Thermal, and Mechanical Properties of Zinc Borate and Synergic Fire Retardants on Composites Produced with PP-MDF Wastes
}

\author{
Ertugrul Altuntas, ${ }^{*}$ Nasir Narlioglu, and Mehmet Hakki Alma \\ Synergic effects of different fire retardant compounds and zinc borate on \\ wood-plastic composites filled with polypropylene (PP) and medium- \\ density fiberboard (MDF) waste fibers were investigated. For this \\ purpose, zinc borate, synergic compounds (antimony trioxide, \\ ammonium phosphate, and magnesium hydroxide), and a coupling \\ agent, i.e., maleic anhydride-grafted polypropylene (MAPP), were used \\ in the production of wood-plastic composites (WPCs). The composite \\ samples were characterized in terms of the burning rate and limiting \\ oxygen index (LOI) analyses, thermal gravimetric analysis (TGA), and \\ differential scanning calorimetry (DSC) along with mechanical tests, i.e., \\ flexural properties, tensile properties, elasticity modulus, and impact \\ strength. It was found that the synergic influence of the combination of \\ zinc borate, antimony trioxide, and magnesium oxide on WPCs \\ increased the heat resistance according to the burning rate, LOI, TGA, \\ and DSC tests. Also, the mechanical properties of the WPCs decreased \\ slightly, but their elasticity modulus increased.
}

Keywords: Fire retardant; Thermal properties; Fiber wastes; Zinc borate

Contact information: Department of Forest Biology and Wood Protection Technology, Forestry Faculty, Kahramanmaras Sutcu Imam University, Kahramanmaras, Turkey;

*Corresponding author: ertugrulaltuntas@gmail.com

\section{INTRODUCTION}

The WPCs have been used recently in different construction and building applications due to economic and environmental concerns. These fabricated materials have many advantages, such as lower resin costs, improved stiffness, and improved dimensional stability. Composites that are reinforced with lignocellulosic waste can reduce the use of petroleum-based plastics (Jeencham et al. 2014; Ozdemir et al. 2014).

In the production of WPCs the starting materials are wood and plastics, i.e., thermoplastic and thermoset materials (Jeencham et al. 2014). Lignocellulose materials, such as sawdust, annual crops, and forest waste, can be used in the production of WPCs. Therefore, the use of WPCs has been increasing, and they consist of different lignocellulose wastes and plastics that provide positive performance and reduced cost (Faruk et al. 2007). Compatibilizers, such as maleic anhydride grafted polypropylene (MAPP), are often used in the production of composites to eliminate the incompatibility between wood and plastics (Kurt and Mengeloglu 2011). However, WPCs also have some disadvantages. One of the most serious disadvantages of using WPCs in houses is the high flammability of the lignocellulosic and plastic materials (Umemura et al. 2014). This is especially important because composite products used in such construction may be exposed to the fire hazards. However, the use of boron compounds, such as zinc borate 
and boric acid, in the production of WPCs provides protection against fire. Boron compounds have been also used to protect wood from fungi and insects (Ayrilmis 2013; Turku et al. 2014). In addition, boron compounds have been used to reduce the thermal degradation of composite materials. Many fire-retardant compounds are available for polymer composites, including ammonium phosphate, diammonium phosphate, magnesium hydroxide, and aluminum trihydrate. Many studies have shown that the synergic effect between boron compounds, such as zinc borate, and other compounds, such as ammonium phosphate, diammonium phosphate, magnesium hydroxide, antimony trioxide, and aluminum trihydrate, provides a heat barrier for WPCs (Ning and Guo 2000; Kurt and Mengeloglu 2011; Arao et al. 2014; Jeencham et al. 2014; Turku et al. 2014; Umemura et al. 2014; $\mathrm{Wu}$ and $\mathrm{Xu}$ 2014). The amount of fire retardants used in the formulation of WPCs must be carefully controlled because the mechanical properties of composites may be adversely affected due to excessive usage of these compounds (Turku et al. 2014).

This research investigates the synergic effect between the zinc borate and various fire retardant compounds on the flammable properties of $\mathrm{MDFw}$-filled PP composites. The relationship between zinc borate and MAPP was also investigated. A thermal gravimetric analyzer (TGA) and differential scanning calorimetry (DSC) were used to investigate the thermal resistance properties. Moreover, the horizontal burning rate and limiting oxygen index (LOI) tests of samples were carry out to determine the effects of the fire retardants on the stability of the fire properties. The effects of the fire retardants on the mechanical properties of the WPCs were also determined, including their tensile, flexural, and impact strengths, as well as their flexural and tensile modulus.

\section{EXPERIMENTAL}

\section{Materials}

The MDF particles were obtained from the Kastamonu Entegre Co. (Adana, Turkey). These fiber particles were separated into 60-mesh fibers using screens, and the fibers were oven-dried before the manufacturing process. Polypropylene (PP, density: $0.946 \mathrm{~g} / \mathrm{cm}^{3}$ ) and paraffin wax were provided by the Petkim Petrochemical Co. (Izmir, Turkey). Maleic anhydride grafted polypropylene, used as a coupling agent in some composite boards, was supplied by Clariant International Co. (Shanghai, China). Zinc borate $\left(\mathrm{ZnO} \cdot 2 \mathrm{~B}_{2} \mathrm{O}_{3} \cdot 3.5 \mathrm{H}_{2} \mathrm{O}\right)$ was obtained from the Aromos Chemistry Co. (Izmir, Turkey). Antimony trioxide $\left(\mathrm{Sb}_{2} \mathrm{O}_{3}\right)$, and ammonium phosphate $\left(\left(\mathrm{NH}_{4}\right)_{3} \mathrm{PO}_{4}\right)$ were obtained from Tekkim Chemistry Co. (Istanbul, Turkey). Magnesium hydroxide $\left(\mathrm{Mg}(\mathrm{OH})_{2}\right)$ were obtained from the Zag Chemistry Co. (Istanbul, Turkey).

\section{Methods}

The oven-dried MDFw $\left(103{ }^{\circ} \mathrm{C}\right)$, PP, MAPP, zinc borate $(\mathrm{ZB})$, antimony trioxide (AT), ammonium phosphate (AP), and magnesium hydroxide (MH) were prepared according to Table 1 for the composite samples. Prepared materials were mixed with a high-speed mixer (speed range $5 \mathrm{rpm}$ to $1000 \mathrm{rpm}$ for $5 \mathrm{~min}$ ) before the extrusion process. A twin-screw extruder was used to produce the composites; the temperatures of the extruder barrel were set at $175^{\circ} \mathrm{C}, 180{ }^{\circ} \mathrm{C}, 185^{\circ} \mathrm{C}, 190{ }^{\circ} \mathrm{C}$, and $190{ }^{\circ} \mathrm{C}$ for the warm regions of the extruder: $1,2,3,4$, and 5 , respectively. The temperature of the extruder die 
zone averaged around $195{ }^{\circ} \mathrm{C}$. The extruded composite products were sufficiently pelletized. The extruded composite pellets were first oven-dried until the moisture content of the pellets reached $1 \%$ to $2 \%$. Then, the fabrication process of the composites was carried out using the hot press machine. These pellets were pressed for $10 \mathrm{~min}$ at 180 ${ }^{\circ} \mathrm{C}$ and 100 bar pressure. The specimens from the composite boards were sized and cut according to related ASTM standards for experimental examples and conditioned in respect to ASTM D618 (2013).

Table 1. Weight Percentages of WDFw Filled Wood Plastic Composites

\begin{tabular}{|l|c|c|c|c|c|c|c|c|}
\hline \multicolumn{8}{|c|}{ Composition Based on Weight (\%) } \\
\hline Sample Code & $\begin{array}{c}\text { MDF } \\
\text { wastes }\end{array}$ & PP & MAPP & $\begin{array}{c}\text { Zinc } \\
\text { Borate }\end{array}$ & $\begin{array}{c}\text { Ammonium } \\
\text { Phosphate }\end{array}$ & $\begin{array}{c}\text { Antimony } \\
\text { Trioxide }\end{array}$ & $\begin{array}{c}\text { Magnesium } \\
\text { Hydroxide }\end{array}$ & Wax \\
\hline Control & 40 & 59 & & & & & & 1 \\
\hline PP/MAPP & 40 & 56 & 3 & & & & & 1 \\
\hline PP/ZB & 40 & 47 & & 12 & & & & 1 \\
\hline PP/MAPP/ZB & 40 & 44 & 3 & 12 & & & & 1 \\
\hline PP/ZB/AP & 40 & 47 & & 6 & 6 & & & 1 \\
\hline PP/ZB/AT & 40 & 47 & & 6 & & 6 & & 1 \\
\hline PP/ZB/MH & 40 & 47 & & 6 & & & 6 & 1 \\
\hline PP/ZB/AP/AT & 40 & 47 & & 4 & 4 & 4 & & 1 \\
\hline
\end{tabular}

Flame retardancy and Limiting Oxygen Index (LOI) performance

The flame retardancy of composites was determined via horizontal burning tests according to ASTM D635 (2014). Composite samples with five replicates for each group were tested using an Atlas HVUL2 horizontal-vertical flame chamber. For the horizontal burning tests, the composite samples were horizontally held from one end and the free end of the composite sample was exposed to flame fueled by oxygen. The time needed for the flame to reach from the first reference point to the second reference point was measured. The distance between the two reference points is $75 \mathrm{~mm}$.

The limiting oxygen index (LOI) test was performed according to ASTM D286310 (2000) using a limiting oxygen index chamber (Dynisco, Heilbronn, Germany). For LOI, the composite samples were vertically placed using a holder in the glass tube. The medium oxygen concentration was used to support combustion during the tests. The head of the composite sample was ignited and minimum oxygen concentrations which would support combustion were recorded as a percentage.

\section{Thermal Gravimetric Analysis (TGA)}

The TGA analyses were carried out to investigate the decomposition behavior of composite samples in this research. Powdered test samples were used for the thermogravimetric analysis. The analysis was performed using a Shimadzu TGA-50 thermal analyzer (Shimadzu, Tokyo, Japan) at a heating rate of $10{ }^{\circ} \mathrm{C} / \mathrm{min}$ up to $800{ }^{\circ} \mathrm{C}$ under a nitrogen flow of $50 \mathrm{~mL} / \mathrm{min}$.

\section{Differential Scanning Calorimetry Analysis}

Powdered test samples were used for the DSC. The DSC analyses were performed in a Shimadzu DSC-60 differential scanning calorimeter (Shimadzu, Tokyo, Japan) at a heating rate of $10^{\circ} \mathrm{C} / \mathrm{min}$ up to $200{ }^{\circ} \mathrm{C}$ under a nitrogen flow of $100 \mathrm{~mL} / \mathrm{min}$ according to 
ASTM D3418 (2008). For the samples, the melting temperature, the second melting enthalpy $\left(\Delta H_{\mathrm{m}}\right)$, the crystallization peak temperature, and crystallization enthalpy were measured, and the degree of crystallinity $\left(X_{\mathrm{cd}}, \%\right)$ was calculated using Eq. 1 (Joseph et al. 2003).

$$
X_{\mathrm{cd}}=\frac{\Delta H_{m}}{(1-x)-\Delta H_{p p}} \times 100
$$

In this formula, $\Delta H_{\mathrm{pp}}$ is the melting enthalpy $(209 \mathrm{~J} / \mathrm{m})$ value of the $100 \%$ crystalline form of pure PP and (1-x) shows the weight ratio of PP in the composite examples.

\section{Mechanical Properties}

The tensile strength (TS) and modulus of elasticity were determined according to ASTM D638 (2007) with a crosshead speed of $5 \mathrm{~mm} / \mathrm{min}$ and load cell of $0.1 \mathrm{kN}$. The flexural strength (FS) was determined according to ASTM D790 (2007) with a crosshead speed of $2 \mathrm{~mm} / \mathrm{min}$ using a universal testing machine (Zwick/Roel, model Z010, Stuttgart, Germany) at room temperature. Impact testing was carried out with a pendulum impact tester (Zwick, HIT5.5P, Stuttgart, Germany), at room temperature, according to ASTM D256 (2007). The notches were made using a notching cutter (Ray-Ran Test Equipment, Ltd., Polytest; Nuneaton, UK). Eight samples were tested for the tensile, flexural, and impact tests.

Scanning Electron Microscopy (SEM) analysis of decayed composites

The morphological properties and the distribution of fire retardants in MDFwfilled PP composites was recorded using a JEOL Neo Scope JSM-500 (JEOL Co, Freising, Germany) scanning electron microscope under an acceleration voltage of 10 $\mathrm{kV}$. The specimens were coated with gold (Cressington Scientific Instruments Co, Watford, England) under vacuum prior to scanning.

\section{Statistical analysis}

The statistical evaluation of the mechanical test results was performed using the SPSS 20.0 statistical analysis program. The data were subjected to ANOVA variance analysis at $\mathrm{p} \leq 0.05$ confidence level, and significant differences between mean sample values were obtained according to the Duncan multiple range test. The significant differences between the groups are expressed in capital letters A, B, C and D.

\section{RESULTS AND DISCUSSION}

\section{Flame Retardancy and Limiting Oxygen Index Results}

Table 2 shows the burning rates of the composites, which ranged from $16 \mathrm{~mm} / \mathrm{min}$ to $32 \mathrm{~mm} / \mathrm{min}$. The PP/ZB/AP/AT composite had the lowest burning rate. The burning rate of the PP/MAPP composite were reduced when compared the control group. Also, the burning rate of PP/MAPP/ZB was affected adversely in comparison with the PP/ZB because the addition of MAPP resulted in a tighter texture in the composite material. Various studies have shown that the addition of MAPP or MAPE into WPCs increased their burning rate (Sain et al. 2004; Kurt and Mengeloglu 2011; Cavdar et al. 2016).

The composites prepared by mixing zinc borate were compared to other fire retardant added samples to determine their synergic effect. Table 2 shows that the fire 
resistances of $\mathrm{PP} / \mathrm{ZB} / \mathrm{AP}, \mathrm{PP} / \mathrm{ZB} / \mathrm{AT}$, and $\mathrm{PP} / \mathrm{ZB} / \mathrm{MH}$ had a synergic effect on the burning rate, decreasing it 55\%, 44\%, and 35\%, respectively, compared to the control group. The lowest burning rate was observed when zinc borate, antimony trioxide, and ammonium phosphate were used together in the WPCs. Other studies have been conducted to reduce the burning rate related to the synergic effect in WPCs (Kurt and Mengeloglu 2011).

The LOI results of the WPCs were shown in Table 2. The highest values were obtained when using PP/ZB/AP and PP/ZB/AT. It was understood that the synergic compounds, such as antimony trioxide, ammonium phosphate, and magnesium hydroxide, have an effect on the LOI when they are used in the WPCs. Aluminum polyphosphate was used in an earlier study, and it was concluded that greater amounts of fire retardants improved the LOI results (Zhang et al. 2012). In another study about fire retardant added WPCs, it was found that addition of $10 \%$ aluminum polyphosphate to composite material resulted in self-extinguishing properties. The addition of aluminum polyphosphate to the composite material formed a layer on the composite surface. This layer prevented the passage of oxygen (Arao et al. 2014).

Table 2. Burning Rate and LOI Results of Composites

\begin{tabular}{|l|c|c|}
\hline Sample Codes & Burning Rate $(\mathrm{mm} / \mathrm{min})$ & LOI (Oxygen $\%)$ \\
\hline Control & $30.5\left(1.87^{\star}\right)$ & $20 \% \pm 0.2 \%$ \\
\hline PP/MAPP & $31.8(2.24)$ & $21 \% \pm 0.2 \%$ \\
\hline PP/ZB & $18.5(0.75)$ & $21 \% \pm 0.2 \%$ \\
\hline PP/MAPP/ZB & $26.7(1.80)$ & $21 \% \pm 0.2 \%$ \\
\hline PP/ZB/AP & $22.6(1.09)$ & $22 \% \pm 0.2 \%$ \\
\hline PP/ZB/AT & $16.9(1.85)$ & $22 \% \pm 0.2 \%$ \\
\hline PP/ZB/MH & $19.9(2.95)$ & $22 \% \pm 0.2 \%$ \\
\hline PP/ZB/AP/AT & $15.5(0.83)$ & $22 \% \pm 0.2 \%$ \\
\hline
\end{tabular}

${ }^{*}$ Standard deviation

\section{Thermal Gravimetric Analyze Results}

The TGA results are given in Table 3, and they indicated that the degradation of all of the samples took place in two main steps. The first step was within the temperature range of $250{ }^{\circ} \mathrm{C}$ to $395{ }^{\circ} \mathrm{C}$, and the second step was between $395{ }^{\circ} \mathrm{C}$ and $510{ }^{\circ} \mathrm{C}$. It was concluded that the lignocellulosic material deteriorated in the first stage and the plastic material deteriorated in the second stage. Based on a comparison with the control group, it was apparent that all of the fire-retardant agents greatly improved the thermal characteristics of the composites. However, when MAPP was added alone into the formulation of the control, the thermal resistance of the composite material was diminished, and the residual amount of the material decreased approximately $30 \%$ in comparison with the control group. This result may have been due to the crosslinking of the MAPP with the polymer and MDFw, which produced a positive influence on the thermal conductivity of the composite. Lignocellulosic degradation in the temperature range of $200{ }^{\circ} \mathrm{C}$ to $350{ }^{\circ} \mathrm{C}$ was associated with to hemicellulose and cellulose, and the degradation of lignin occurred in the temperature range of $250{ }^{\circ} \mathrm{C}$ to $500{ }^{\circ} \mathrm{C}$ (Jeske et al. 2012; Arao et al. 2014).

The synergistic effect of zinc borate was mainly reflected in the first and second degradation stage. Moreover, according to the DTGA curve in Fig. 1, it was understood 
that curves of composite samples with synergistically effective compounds had a lower peak area than that of control and PP/MAPP samples.

Table 3. Thermal Gravimetric Analyze Results of Composites

\begin{tabular}{|c|c|c|c|c|c|}
\hline \multirow{2}{*}{ Samples } & \multirow{2}{*}{$\begin{array}{c}\text { 1st Degradation } \\
\text { Stage Temperature } \\
\text { Range }\left({ }^{\circ} \mathrm{C}\right)\end{array}$} & \multirow{2}{*}{$\begin{array}{c}\text { 2nd Degradation } \\
\text { Stage Temperature } \\
\text { Range }\left({ }^{\circ} \mathrm{C}\right)\end{array}$} & \multicolumn{2}{|c|}{ Weight Loss $\left({ }^{\circ} \mathrm{C}\right)$} & \multirow{2}{*}{$\begin{array}{l}\% \text { Residue } \\
\text { at } 800\left({ }^{\circ} \mathrm{C}\right)\end{array}$} \\
\hline & & & $5 \%$ & $50 \%$ & \\
\hline Control & $25-392$ & $396-504$ & 281 & 465 & 4.5 \\
\hline PP/MAPP & $250-393$ & $393-508$ & 287 & 466 & 3 \\
\hline $\mathrm{PP} / \mathrm{ZB}$ & $262-394$ & $406-509$ & 289 & 476 & 16.5 \\
\hline PP/MAPP/ZB & $261-394$ & $403-512$ & 274 & 477 & 17 \\
\hline $\mathrm{PP} / \mathrm{ZB} / \mathrm{AP}$ & $262-379$ & $411-500$ & 290 & 475 & 13.5 \\
\hline PP/ZB/AT & $255-386$ & $399-509$ & 282 & 478 & 20 \\
\hline PP/ZB/MH & $255-285$ & $396-509$ & 281 & 477 & 17 \\
\hline PP/ZB/AP/AT & $255-386$ & $398-506$ & 280 & 476 & 17.4 \\
\hline
\end{tabular}

The combined usage of zinc borate and antimony trioxide was very effective to increase the thermal stability of the WPC sample, where the thermal degradation of the WPC samples was not initiated until the temperature reached the second degradation region. Compared to the control sample, it was clear that the addition of fire retardants in the formulations greatly reduced the total weight loss ratio and increased the residual amount at $800{ }^{\circ} \mathrm{C}$. The best increase in fire resistance of the WPCs against thermal degradation occurred in the sample that contained zinc borate and ammonium phosphate. The weight loss ratio of PP/ZB/AT was reduced approximately 15\% compared to the control sample. From the various fire-retardant chemicals used, zinc borate with MAPP and zinc borate in combination with ammonium phosphate and magnesium hydroxide had the most positive effect on the thermal resistance of the WPCs.
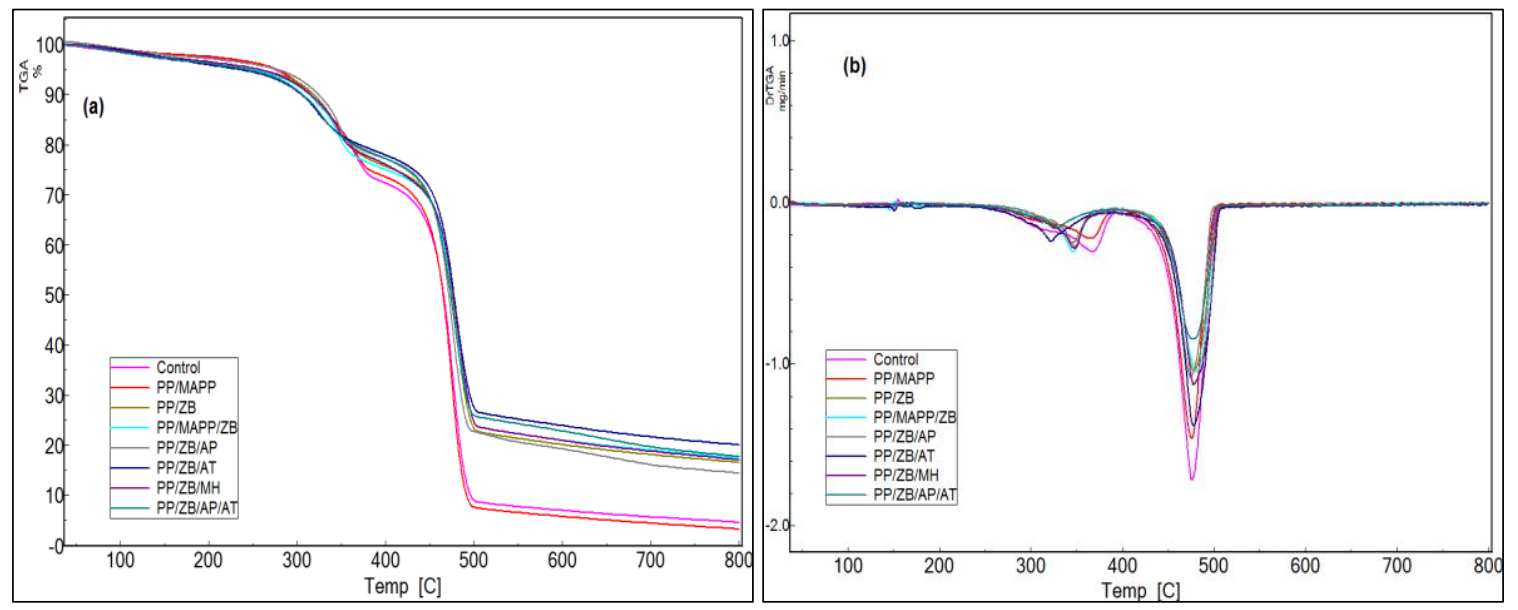

Fig. 1. TGA (a) and DTGA (b) Curves of Composite Samples

\section{Differential Scanning Calorimetry (DSC) Results}

The DSC results of the WPCs are presented in Table 4. The melting points of the WPCs that were filled with different fire retardants were lower than the melting point of the unfilled polypropylene composite. The WPC sample with the lowest melting point (i.e., $161.7^{\circ} \mathrm{C}$ ) was PP/ZB/AT. The WPCs that contained fire retardants had higher peak crystallization temperatures than that of the control sample $\left(116{ }^{\circ} \mathrm{C}\right)$ without fire 
retardants. The peak crystallization temperature of the composites ranged from $116{ }^{\circ} \mathrm{C}$ to $119.5{ }^{\circ} \mathrm{C}$. The crystallization enthalpy of the control samples was $50.6 \mathrm{~J} / \mathrm{g}$. The crystallization enthalpy of the composite samples ranged from $50.6 \mathrm{~J} / \mathrm{g}$ to $39.5 \mathrm{~J} / \mathrm{g}$. These results indicated that the thermal stabilities of the composites varied, dependent upon the fire retardant. The PP/ZB/AT sample emitted more heat energy in the crystallization of the composites. The crystallization of the composite generally increased with the addition of the various fire retardants. It was assumed that this occurred due to the minor degradation of the polymer matrix. As the lengths of the polymer chains were reduced, the crystallization levels of the polymers increased (Ayadi et al. 2012; Akesson et al. 2016; Ichazo et al. 2001). The crystallites $\left(X_{\mathrm{cd}}\right)$ of the composite samples ranged frorm $33.7 \%$ to $50.1 \%$. Fire retardants with synergistic effect added to composite samples generally increased the degree of crystallinity. The $X_{\mathrm{cd}}$ of the control sample was $35.8 \%$, while the highest $X_{\mathrm{cd}}$ was found as $50.1 \%$ for PP/ZB/AT sample.

Table 4. Differential Scanning Calorimeter Results of Composites

\begin{tabular}{|c|c|c|c|c|c|c|}
\hline Samples & $\begin{array}{c}\text { 1st Melting } \\
\text { Temperature } \\
\left({ }^{\circ} \mathrm{C}\right)\end{array}$ & $\begin{array}{c}\text { 2nd Melting } \\
\text { Temperature } \\
\left({ }^{\circ} \mathrm{C}\right)\end{array}$ & $\begin{array}{c}\text { 2nd Melting } \\
\text { Enthalpy } \\
(\mathrm{J} / \mathrm{g})\end{array}$ & $\begin{array}{c}\text { Crystallization } \\
\text { Temperature } \\
\left({ }^{\circ} \mathrm{C}\right)\end{array}$ & $\begin{array}{c}\text { Crystallization } \\
\text { Enthalpy } \\
(\mathrm{J} / \mathrm{g})\end{array}$ & $\begin{array}{c}X_{\mathrm{cd}} \\
(\%)\end{array}$ \\
\hline Control & 163.8 & 163.1 & 44.1 & 116 & 50.6 & 35.8 \\
\hline PP/MAPP & 163.1 & 162.1 & 46.6 & 115.8 & 48.1 & 39.8 \\
\hline PP/ZB & 163.5 & 162.9 & 39.3 & 117.5 & 42.3 & 40.0 \\
\hline PP/MAPP/ZB & 162.5 & 162.4 & 41 & 117.3 & 47 & 44.6 \\
\hline PP/ZB/AP & 162 & 161.8 & 45.5 & 118.5 & 47.1 & 46.3 \\
\hline PP/ZB/AT & 161.8 & 161.7 & 49.2 & 117.5 & 50.8 & 50.1 \\
\hline PP/ZB/MH & 161.9 & 161.8 & 33.1 & 119.5 & 39.5 & 33.7 \\
\hline PP/ZB/AP/AT & 162.8 & 162.6 & 43.7 & 117.9 & 45.3 & 44.5 \\
\hline
\end{tabular}
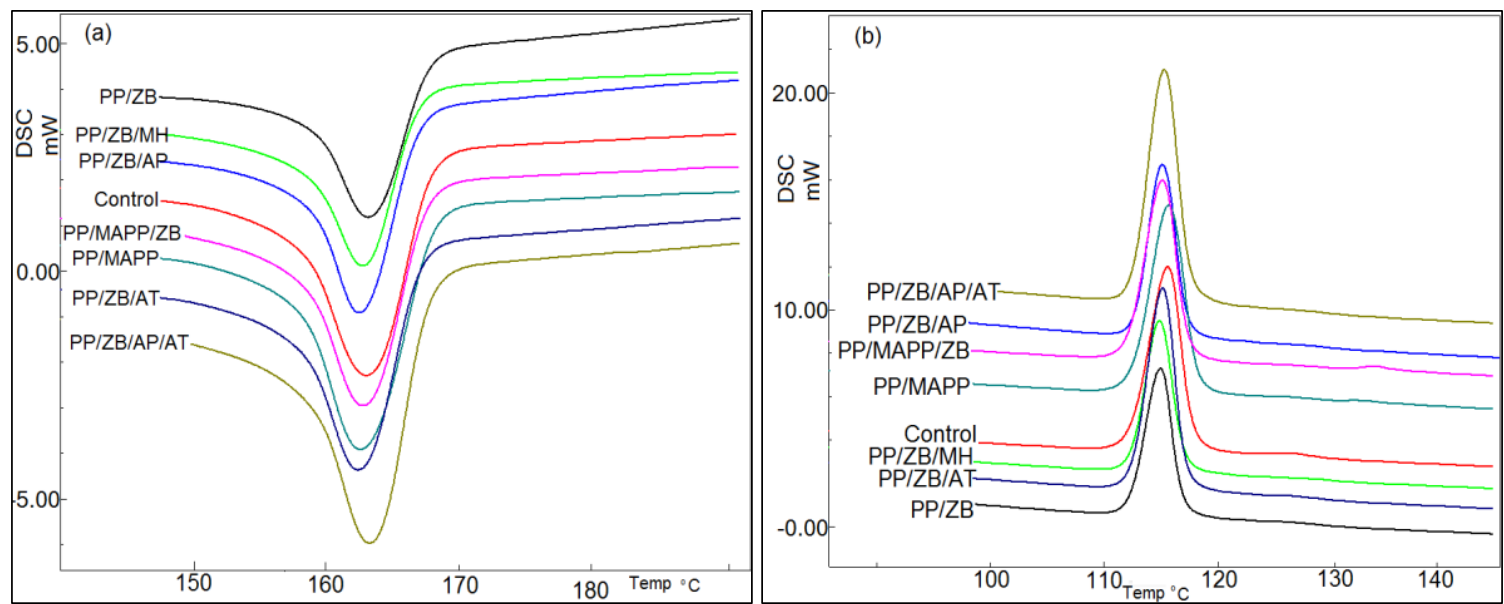

Fig. 2. DSC results of the composites: a) Melting, b) Crystallization Temperature

\section{Results of the Mechanical Analysis}

Table 5 shows the tensile strengths and elastic modulus of the composite samples. The effects of the fire retardants and MAPP on the tensile strengths and elasticity modulus of the composite samples are demonstrated in Fig 3. The addition of zinc borate as a fire retardant slightly reduced $(11 \%)$ the tensile strength $(13.22 \mathrm{MPa})$ but increased the elasticity modulus (909.7 MPa) of the PP/ZB composite. The addition of only $3 \%$ 
MAPP in the composite sample increased the tensile strength $(16.59 \mathrm{MPa})$ and elasticity modulus (842.89 MPa) of PP/MAPP. Moreover, using both 3\% MAPP and zinc borate increased the tensile strength and the elasticity modulus in comparison with the control sample. It was determined that, without the addition of MAPP, the tensile strength and elasticity modulus of PP/MAPP/ZB were lower than those of the control group. It was reported that adding high levels of fire retardants, such as zinc borate, magnesium hydroxide, and ammonium phosphate, into polymer composites has a negative effect on the tensile strength (Arao et al. 2014; Umemura et al. 2014). The addition of various synergic fire retardant compounds with zinc borate to the WPCs generally reduced the tensile elastic modulus (TEM). When antimony trioxide, ammonium phosphate, and magnesium hydroxide were added separately to the WPCs, the strengths of the WPCs decreased $30 \%, 41 \%$, and $6 \%$, respectively. However, the addition of magnesium hydroxide increased the elasticity modulus (12\%) of PP/ZB/MH sample according to the control sample. In a study, the fire retardant properties of composite samples with aluminum polyphosphate at different ratios were examined. Consequently, it was reported that the usage of fire retardants adversely affected the mechanical properties of composites (Arao et al. 2014).

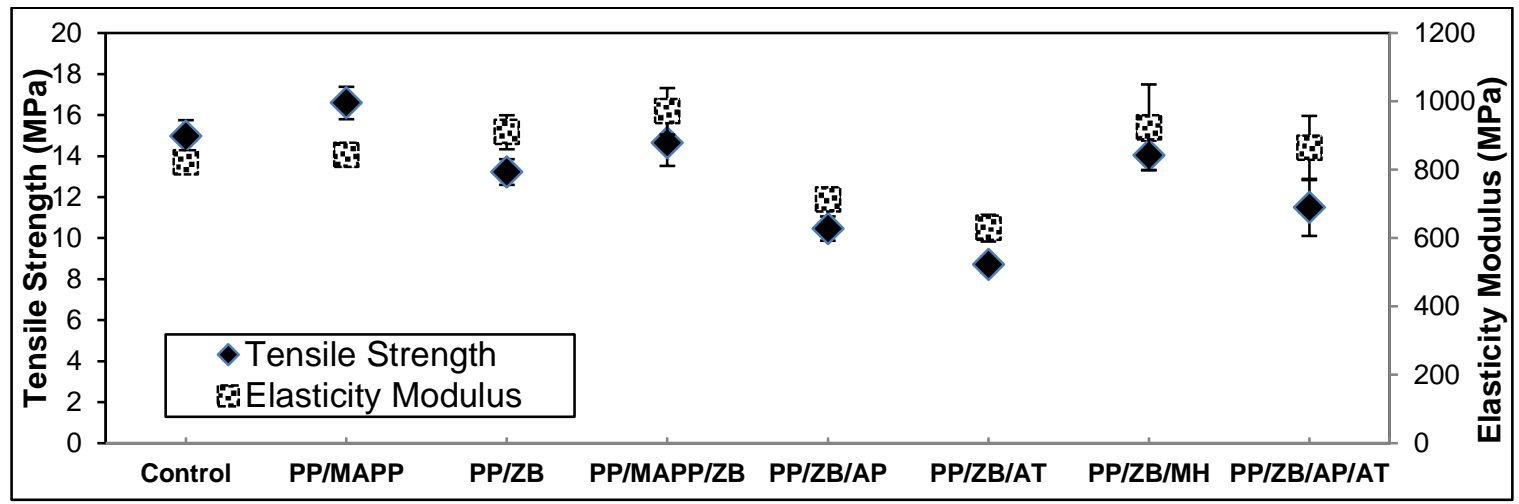

Fig. 3. Tensile strength and elasticity modulus of composite samples

Table 5. Mechanical Tests Results of Composites

\begin{tabular}{|c|c|c|c|c|c|c|c|c|c|c|}
\hline & \multicolumn{4}{|c|}{ Tensile Properties } & \multicolumn{4}{c|}{ Flexural Properties } & \multicolumn{3}{c|}{$\begin{array}{c}\text { Impact } \\
\text { Strength }\end{array}$} \\
\cline { 2 - 12 } Samples & $\begin{array}{c}\text { TS } \\
(\mathrm{MPa})\end{array}$ & Sd $^{\mathrm{a}}$ & $\begin{array}{c}\text { TEM } \\
(\mathrm{MPa})\end{array}$ & $\mathrm{Sd}$ & $\begin{array}{c}\text { FS } \\
(\mathrm{MPa})\end{array}$ & Sd & $\begin{array}{c}\text { FEM } \\
(\mathrm{MPa})\end{array}$ & $\mathrm{Sd}$ & $\begin{array}{c}\text { IS } \\
(\mathrm{J} / \mathrm{m})\end{array}$ & $\mathrm{Sd}$ \\
\hline Control & $14.96^{E, \mathrm{~b}}$ & 0.79 & $821.29^{C}$ & 31.9 & $37.37^{E}$ & 2.1 & $2158.6^{C}$ & 162.7 & $22.6^{D}$ & 1.7 \\
\hline PP/MAPP & $16.59^{F}$ & 0.79 & $842.89^{C D}$ & 32.0 & $38.84^{E}$ & 3.2 & $2216.1^{C}$ & 113.8 & $20.9^{C D}$ & 1.1 \\
\hline PP/ZB & $13.22^{D}$ & 0.63 & $909.70^{D E}$ & 49.7 & $29.31^{D}$ & 1.8 & $2297.4^{C D}$ & 140.7 & $23.4^{D}$ & 2.4 \\
\hline PP/MAPP/ZB & $14.64^{E}$ & 1.12 & $970.90^{E}$ & 68 & $32.01^{C}$ & 1.5 & $2442.4^{D}$ & 96.8 & $22.3^{D}$ & 1.5 \\
\hline PP/ZB/AP & $10.46^{B}$ & 0.59 & $712.12^{B}$ & 25.3 & $22.42^{A}$ & 1.8 & $1579.4^{A}$ & 108.8 & $18.8^{B C}$ & 1.9 \\
\hline PP/ZB/AT & $8.70^{A}$ & 0.42 & $629.13^{A}$ & 39.1 & $21.65^{A}$ & 2.4 & $1705.9^{A}$ & 128.1 & $14.3^{A}$ & 2.3 \\
\hline PP/ZB/MH & $14.04^{D E}$ & 0.72 & $922.63^{D E}$ & 128.8 & $30.79^{C D}$ & 1.1 & $2159.3^{C}$ & 200.6 & $21.8^{D}$ & 1.1 \\
\hline PP/ZB/AP/AT & $11.50^{C}$ & 1.39 & $863.60^{C D}$ & 93.8 & $25.13^{B}$ & 2.4 & $1945.3^{B}$ & 73.3 & $17.7^{B}$ & 0.9 \\
\hline
\end{tabular}

aStandard deviation, bHomogeneity groups with superscripts were given from lowest to highest in the order letter $(A-F)$ and those around it $(\alpha<0.05)$. The Superscripts indicate the statistical differences between properties of composite samples by Duncan' mean separation test. 
Table 5 shows the flexural strengths and elastic modulus of the WPCs samples. Comparisons of flexural strengths and elasticity modulus of composite samples are given Fig. 4. The results indicated that the addition of zinc borate as a fire retardant material to the PP/ZB composite reduced flexural strength $(21 \%)$ but increased its elastic modulus (6\%) according to control sample. However, the addition of only $3 \%$ MAPP to the WPC increased the flexural strength and elastic modulus of PP/MAPP. In addition, the using both 3\% MAPP and zinc borate reduced the tensile strength and increased the elastic modulus (13\%) compared to the control sample. The addition of different fire retardant compounds with zinc borate in the composite samples generally reduced their flexural strengths and elastic modules according to Fig. 4. The lowest tensile strength and elastic modulus were obtained for the PP/ZB/AT composite, and there were two possible reasons for these effects. The first reason was the formation of a fragile surface between the polymer and zinc borate. The second reason was due to the structural incompatibility between the polymer and the fire retardant (Suppakarn and Jarukumjorn 2009; Ayrilmis 2013; Arao et al. 2014; Turku et al. 2014; Cavdar et al. 2016).

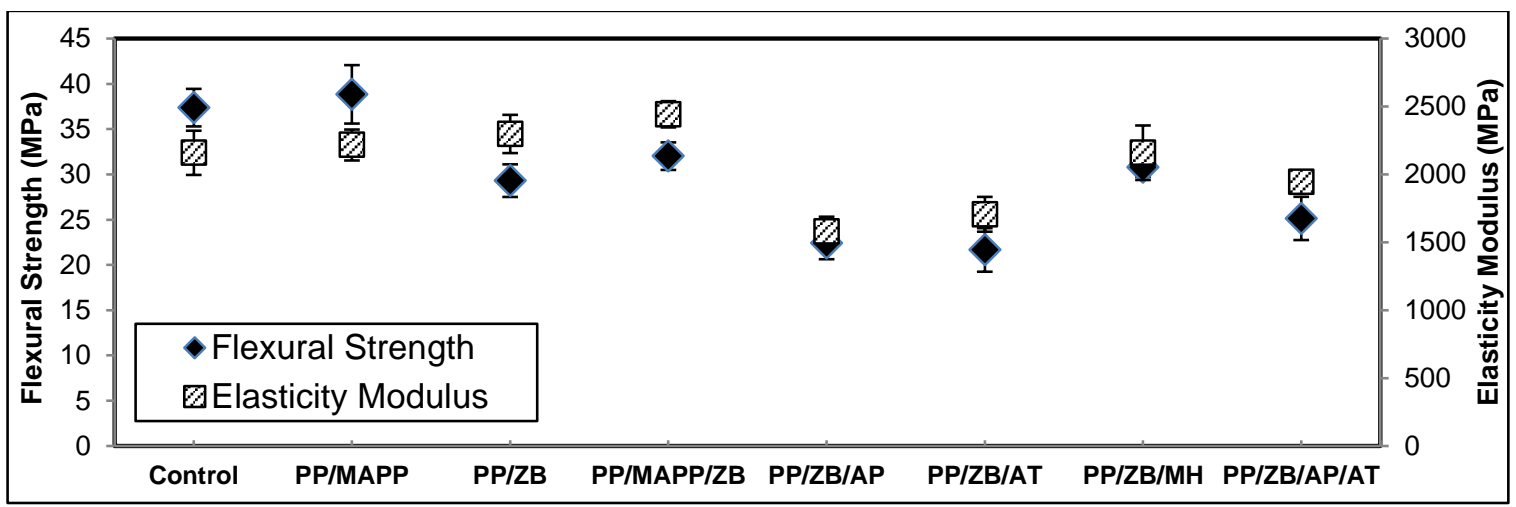

Fig. 4. Flexural strength and elasticity modulus of composite samples

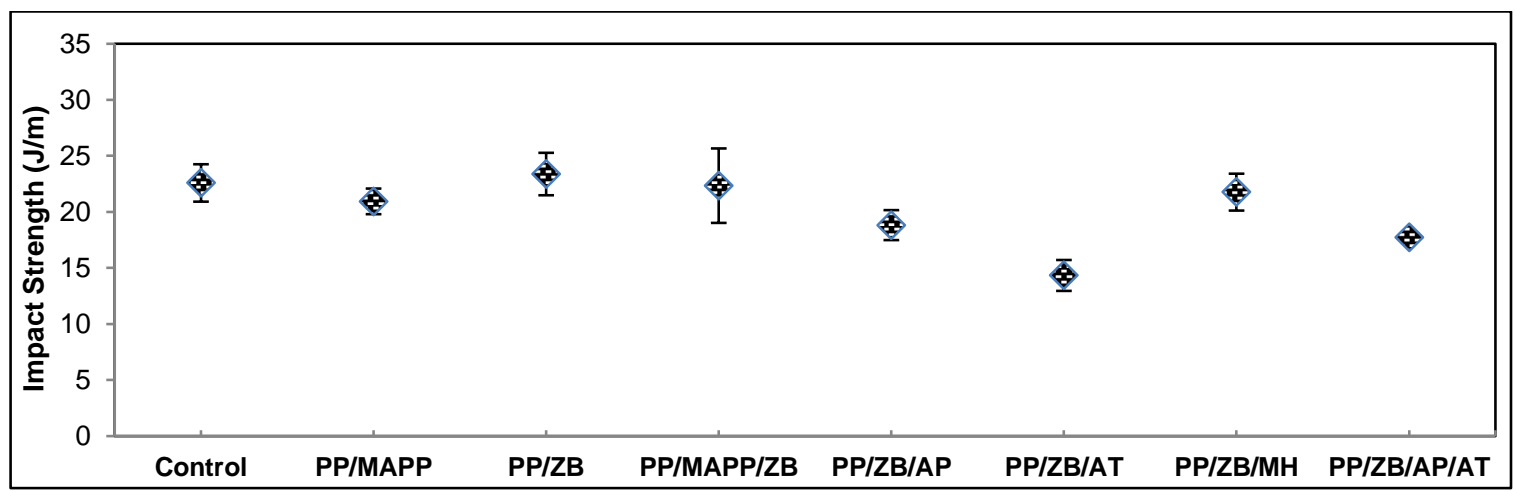

Fig. 5. The impact strengths of composite samples

Table 5 shows the impact strength of the composite samples. The mean values of the composite samples ranged from 14.3 $\mathrm{MPa}$ to 23.4 MPa. Figure 5 shows the impact strengths of composite samples. The impact strengths of the composites decreased slightly after addition of the zinc borate and various fire retardants. The lowest impact strength was obtained for the $\mathrm{PP} / \mathrm{ZB} / \mathrm{AT}$ composite. This reduction in impact resistance was mainly due to the distribution of energy by fire retardants, which are very rigid (Pan 
et al.2012). Different studies have reported that the addition of fire retardants to a composite material generally reduces the impact strength (Suppakarn and Jarukumjorn 2009).

\section{Scanning Electron Microscopy Results}

Figure 6 shows the micrographs of the same composite samples with different fire retardants at fiber loading $40 \%$. The control sample showed a tighter texture than that of the composite samples with zinc borate and other fire retardants. This situation was explained the decrease in the strength properties of composite samples with fire retardant. In a study on wood plastic composites, the reason for the decrease in the mechanical properties of the composite material with fire retardant was explained due to porous formed in structures (Mattos et al. 2014).
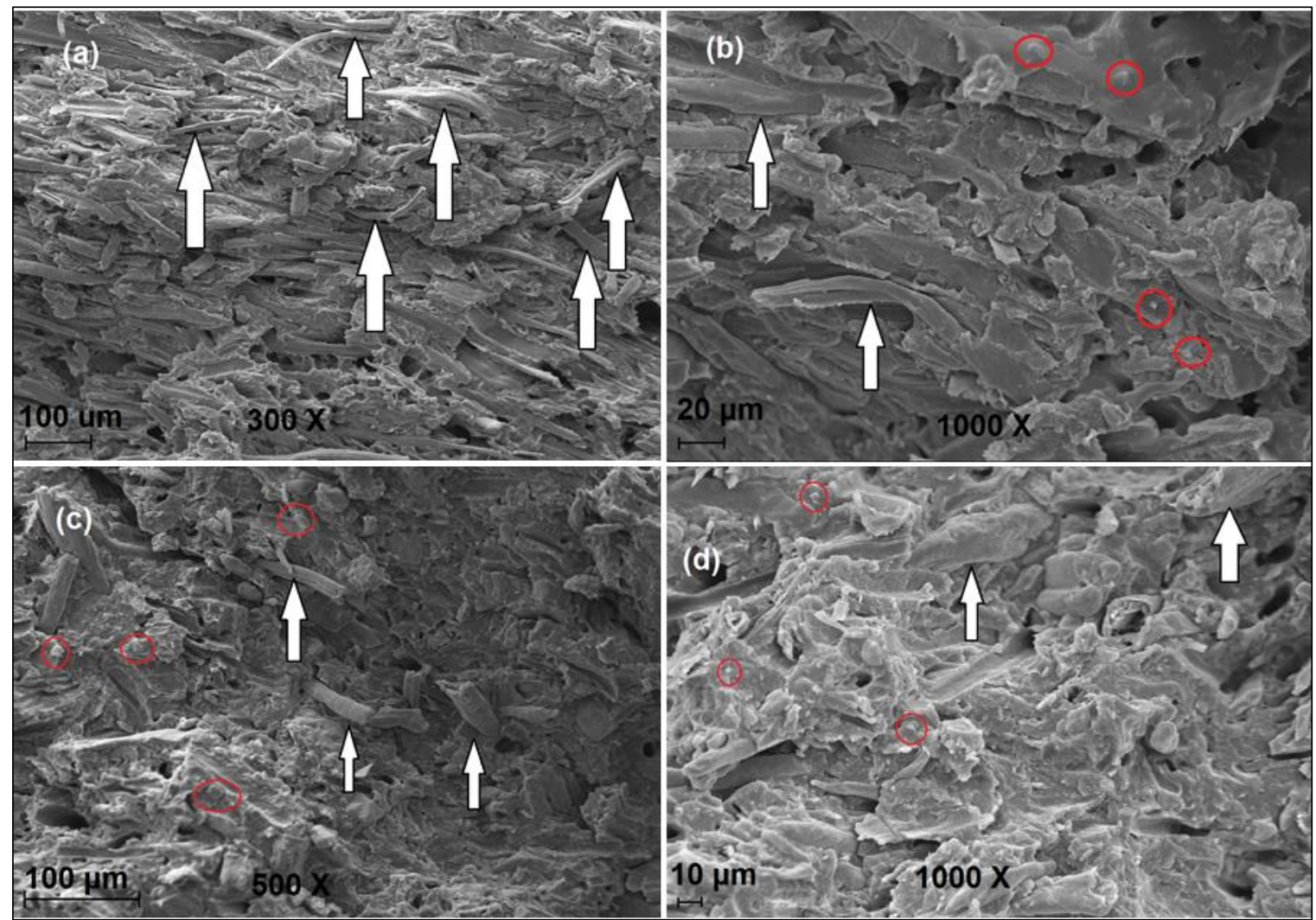

Fig. 6. SEM images of the composite samples a): Control; b): PP/MAPP/ZB; c): PP/ZB/AP and d): fibers in composites; $b$ and $d)$ : PPP/ZB/AP/AT

\section{CONCLUSIONS}

1. The burning rate and limiting oxygen index properties of the composites were improved with the use of fire retardants. Coexistence of zinc borate, antimony trioxide, and ammonium phosphate in the composite created a synergistic effect and had the lowest burning rate. 
2. The burning rates of composites with only zinc borate and together with zinc borate and antimony trioxide were fairly low in comparison to the control sample.

3. The highest limiting oxygen index results were obtained from the composite materials with synergistic effect.

4. According to the thermal gravimetric analyze results, both fire retardants postponed thermal degradation and increased the amount of charring residue at $800{ }^{\circ} \mathrm{C}$. The composite materials with synergistic effect had the higher thermal degradation temperatures.

5. According to the DSC results, zinc borate and various fire retardants reduced the peak melting temperature and increased the peak crystallization temperature. The addition of fire retardants with synergistic effect to composites generally increased the degree of crystallinity.

6. The flexural and tensile strengths of the composites decreased when the fire retardants were used. However, the elastic modulus of the composites with fire retardants was generally affected positively.

7. The use of MAPP increased the tensile strength, flexural strength, and elastic modulus of the samples. The impact strengths of composites negatively affected when the zinc borate and synergistically effective compounds were used together.

\section{ACKNOWLEDGMENTS}

This study was supported by the National Boron Research Institute in Turkey with a project (2012-C0370). The authors would like to thank the National Boron Research Institute and Kahramanmaras Sutcuimam University, Turkey. We also want to thank to Res. Assist. Tufan Salan for his helping during the study.

\section{REFERENCES CITED}

Akesson, D., Fuchs, T., Stoss, M., Root, A., Stenvall, E., and Skrifvars, M. (2016). "Recycling of wood fiber-reinforced HDPE by multiple reprocessing," Journal of Applied Polymer Science 133(35). DOI: 10.1002/App.43877

Arao, Y., Nakamura, S., Tomita, Y., Takakuwa, K., Umemura, T., and Tanaka, T. (2014). "Improvement on fire retardancy of wood flour/polypropylene composites using various fire retardants," Polymer Degradation and Stability 100(1), 79-85. DOI: 10.1016/j.polymdegradstab.2013.12.022

ASTM D256 (2007). "Standard test method for determining the Izod pendulum impact resistance of plastics," ASTM International, West Conshohocken, PA.

ASTM D618 (2013). "Standard practice for conditioning plastics for testing," ASTM International, West Conshohocken, PA.

ASTM D635 (2014). "Standard test method for rate of burning and/or extent and time of burning of plastics in a horizontal position," ASTM International, West Conshohocken, PA.

ASTM D638 (2007). "Standard test method for tensile properties of plastics," ASTM 
International, West Conshohocken, PA.

ASTM D790 (2007). "Standard test method for flexural properties of unreinforced and reinforced plastics and electrical insulating materials," ASTM International, West Conshohocken, PA.

ASTM D2863-10 (2000). "Standard test method for measuring the minimum oxygen concentration to support candle-like combustion of plastics (oxygen index)," ASTM International, West Conshohocken, PA.

ASTM D3418-08 (2008). "Standard test method for transition temperatures and enthalpies of fusion and crystallization of polymers by differential scanning calorimetry," ASTM International, West Conshohocken, PA.

Ayadi, A., Kraiem, D., Bradai, C., and Pimbert, S. (2012). "Recycling effect on mechanical behavior of HDPE/glass fibers at low concentrations," Journal of Thermoplastic Composite Materials 25(5), 523-536. DOI: 10.1177/0892705711411343

Ayrilmis, N. (2013). "Combined effects of boron and compatibilizer on dimensional stability and mechanical properties of wood/HDPE composites," Composites Part BEngineering 44(1), 745-749. DOI: 10.1016/j.compositesb.2012.04.002

Cavdar, A. D., Kalaycioglu, H., and Mengeloglu, F. (2016). "Technological properties of thermoplastic composites filled with fire retardant and tea mill waste fiber," Journal of Composite Materials 50(12), 1627-1634. DOI: 10.1177/0021998315595113

Faruk, O., Bledzki, A. K., and Matuana, L. M. (2007). "Microcellular foamed woodplastic composites by different processes: A review," Macromolecular Materials and Engineering 292(2), 113-127. DOI: 10.1002/mame.200600406

Ichazo, M. N., Albano, C., Gonzalez, J., Perera, R., and Candal, M. V. (2001). "Polypropylene/wood flour composites: Treatments and properties," Composite Structures 54(2-3), 207-214. DOI: 10.1016/S0263-8223(01)00089-7

Jeencham, R., Suppakarn, N., and Jarukumjorn, K. (2014). "Effect of flame retardants on flame retardant, mechanical, and thermal properties of sisal fiber/polypropylene composites," Composites Part B-Engineering 56, 249-253. DOI:

10.1016/j.compositesb.2013.08.012

Jeske, H., Schirp, A., and Cornelius, F. (2012). "Development of a thermogravimetric analysis (TGA) method for quantitative analysis of wood flour and polypropylene in wood plastic composites (WPC)," Thermochimica Acta 543, 165-171. DOI: 10.1016/j.tca.2012.05.016

Joseph, P. V., Joseph, K., Thomas, S., Pillai, C. K. S., Prasad, V. S., Groeninckx, G., and Sarkissova, M. (2003). "The thermal and crystallisation studies of short sisal fibre reinforced polypropylene composites, "Composites Part A: Applied Science and Manufacturing 34(3), 253-266. DOI: 10.1016/S1359-835X(02)00185-9

Kurt, R., and Mengeloglu, F. (2011). "Utilization of boron compounds as synergists with ammonium polyphosphate for flame retardant wood-polymer composites," Turkish Journal of Agriculture and Forestry 35(2), 155-163. DOI: 10.3906/tar-0910-508

Pan, M., Mei, C., and Song, Y. (2012). "A novel fire retardant affects fire performance and mechanical properties of wood flour-high density polyethylene composites," BioResources 7(2), 1760-1770.

Ning, Y., and Guo, S. Y. (2000). "Flame-retardant and smoke-suppressant properties of zinc borate and aluminum trihydrate-filled rigid PVC," Journal of Applied Polymer 
Science 77(14), 3119-3127. DOI: 10.1002/1097-4628(20000929)77:14<3119::AidApp130>3.0.Co;2-N

Mattos, B. D., Misso, A. L., de Cademartori, P. H., de Lima, E. A., Magalhães, W. L., and Gatto, D. A. (2014). "Properties of polypropylene composites filled with a mixture of household waste of mate-tea and wood particles," Construction and Building Materials 61, 60-68. DOI: 10.1016/j.conbuildmat.2014.02.022

Ozdemir, F., Ayrilmis, N., Kaymakci, A., and Kwon, J. H. (2014). "Improving dimensional stability of injection molded wood plastic composites using cold and hot water extraction methods," Maderas. Ciencia y Tecnologia 16(3), 365-372. DOI: 10.4067/S0718-221 x2014005000029

Sain, M., Park, S. H., Suhara, F., and Law, S. (2004). "Flame retardant and mechanical properties of natural fibre-PP composites containing magnesium hydroxide," Polymer Degradation and Stability 83(2), 363-367. DOI: 10.1016/S0141-3910(03)00280-5

Suppakarn, N., and Jarukumjorn, K. (2009). "Mechanical properties and flammability of sisal/PP composites: Effect of flame retardant type and content," Composites Part BEngineering 40(7), 613-618. DOI: 10.1016/j.compositesb.2009.04.005

Turku, I., Nikolaeva, M., and Karki, T. (2014). "The effect of fire retardants on the flammability, mechanical properties, and wettability of co-extruded PP-based woodplastic composites," BioResources 9(1), 1539-1551. DOI: 10.15376/biores.9.1.15391551

Umemura, T., Arao, Y., Nakamura, S., Tomita, Y., and Tanaka, T. (2014). “Synergy effects of wood flour and fire retardants in flammability of wood-plastic composites," 11th Eco-Energy and Materials Science and Engineering (11th Emses) 56, 48-56. DOI: 10.1016/j.egypro.2014.07.130

Wu, G. F., and Xu, M. (2014). "Effects of boron compounds on the mechanical and fire properties of wood-chitosan and high-density polyethylene composites," BioResources 9(3), 4173-4193. DOI: 10.15376/biores.9.3.4173-3193

Zhang, Z. X., Zhang, J., Lu, B. X., Xin, Z. X., Kang, C. K., and Kim, J. K. (2012). "Effect of flame retardants on mechanical properties, flammability and foamability of PP/wood-fiber composites," Composites Part B-Engineering 43(2), 150-158. DOI: 10.1016/j.compositesb.2011.06.020

Article submitted: April 1, 2017; Peer review completed: June 19, 2017: Revisions accepted: August 1, 2017; Published: August 3, 2017.

DOI: 10.15376/biores.12.4.6971-6983 